\title{
Espacios y memoria del mal: en torno a La iniquidad de Alexis Ravelo
}

\section{Spaces and Memory of Evil: On Alexis Ravelo's La iniquidad}

\section{Antonio Becerra Bolaños}

Departamento de Filología Española, Clásica y Árabe, Facultad de Filología de la Universidad de Las Palmas de Gran Canaria. Gran Canaria, España.

antonio.becerra@ulpgc.es

Nayra Pérez Hernández

Escuela de Humanidades, Facultad de Formación General de la Universidad de Las Américas. Quito, Ecuador.

nayra.perez@udla.edu.ec

\section{Resumen}

La noche de piedra (2007) y Los días de Mercurio (2010) son las dos novelas que hasta ahora conforman la trilogía La iniquidad de Alexis Ravelo. Se trata de dos historias de diferente temática y ambientación que entroncan con el hard boiled y el noir y con la mejor tradición de la novela negra española de los años setenta y ochenta, cuyo carácter social y cuya dimensión filosófica recuperan a través de un interesante tratamiento del espacio y de la reconstrucción de la memoria histórica. Asimismo, reformulan el género acogiendo nuevas técnicas narrativas propias de la posmodernidad. Se emparentan, por último, con la neopolicial en nuestro ámbito cultural y se alejan de la nueva novela criminal que triunfa en el mercado editorial.

Palabras clave: novela negra, espacio, memoria histórica, nuevas técnicas narrativas.

\section{Abstract}

La noche de piedra (2007) and Los días de Mercurio (2010) are, until today, the two novels published of the trilogy La Iniquidad by Alexis Ravelo. They present two different stories and settings in the line of hard boiled and noir and in the best tradition of the Spanish thriller from the 70s and 80s, whose social and philosophical dimensions are recovered through an interesting treatment of the space and the reconstruction of historical memory. Ravelo reformulates the genre with narrative techniques typical of postmodernism. His writing is close to the neopolicial genre in our cultural sphere and moves away from the new crime novel that succeeds in the publishing market.

Keywords: Thriller, Space, Historical Memory, New Narrative Techniques. 
Como todos los géneros literarios, el negro o criminal ha dialogado profundamente con el modelo histórico-social que lo envolvía, y aun más quizá debido a su "naturaleza" popular junto con su carácter marginal dentro de la "alta literatura", por el hecho de estar emparentado desde sus orígenes con las revistas pulp, el cine o el cómic. Tanto la gestación como la evolución que experimenta la novela negra han estado unidas, sin lugar a dudas, al desarrollo de la modernidad, como evidencian sus rasgos primigenios (modelo racionalista, afirmación del individuo frente a la sociedad, etc.) o las causas de su explosión tardía en España: "La relación demostrada entre el género negro y el desarrollo de la modernidad ayuda a entender la atrofia del primero en España, un país de histórica modernidad periférica, desigual y dependiente" (Balibrea 114).

El nacimiento del hard boiled en Estados Unidos, y posteriormente del noir francés, como otro estadio del género que superaba aquella primera novela denominada de enigma o policial, evidenciaban una modernidad en crisis, un sistema social capitalista pleno de contradicciones que dejaba a su paso demasiados excluidos. Estas nuevas formas de la literatura criminal llegaban tiroteando las bases del sistema con una potente crítica, al tiempo que cargadas de balas de potencial revolucionario.

A partir de los años ochenta, se evidencia un agotamiento de temas y estructuras que conduce al cierre de importantes colecciones y series, lo que, unido al desencanto de los intelectuales de izquierda, lleva a Jean-Patrick Manchette a proclamar la muerte del néo-polar (López Martínez 177). Pero, en la actualidad, en estas primeras décadas del siglo xxi, vivimos un auge -casi una saturación- del género, hasta el extremo de que se habla incluso del "boom de la novela negra escandinava" (Salgado 3). Así, la pregunta que surge es cómo se ha adaptado el texto negro a estos tiempos de globalización y posmodernidad, donde no hay narratividad posible ni capacidad de situarnos en la historia, como sostiene C. Owen (cit. en Golubov 111). Es decir, si esta ha conservado su naturaleza infame (en el sentido kristeviano de Los poderes de la perversión), de ser vehículo de crítica social, ya que, como sostiene Balibrea, "el crimen no es una aberración temporal sino un rasgo definitorio del mundo contemporáneo, más específicamente urbano” (cit. en López Martínez 182).

A estas alturas, no podemos ser inocentes en la lectura de los fenómenos literarios, y se impone el viejo llamado de atención bourdiano que nos previene del poder editorial y su relación con la producción y la generación de cultura como bien de consumo, lo que presupone la existencia de toda una serie de filtros y sistemas de valoración articulados en torno a los sistemas de selección del objeto libro (Bourdieu 185). Realmente, el género no ha muerto; simplemente se está transformando, ya que, aparte de las operaciones sociocomerciales, el poder tanático de este tipo de literatura es muy poderoso, y continúa siéndolo.

No podemos dejar de mirar el crimen; como lectores no nos salpica la sangre de los asesinatos de papel, pero nos tranquiliza su contemplación, a la vez que saciamos nuestra sed de historias. Pineri sostiene que necesitamos víctimas para sacrificarlas y así desviar la violencia estructural que sentimos (López Martínez 186), aun más 
ante la imposibilidad de poder canalizarla en un mundo despolitizado. Sin embargo, hay un "olvido" de la centralidad-omnipresencia de la muerte en la literatura negra actual: el secreto y valor más profundo de la literatura criminal, parafraseando a López Martínez (183), un hecho humano ineludible del que nacen las grandes preguntas filosóficas sobre el sentido de la existencia humana -incluso Petros Márkaris llega a hablar de la lectura negra como de carácter religioso-, que se hace imposible dentro de una tendencia general (o hegemonía) a la literatura del ensimismamiento que Vázquez Montalván notó hace años.

Con la posmodernidad y el triunfo del pensamiento débil, el género negro se ha blanqueado; así, no es casual que la sentimentalización del (anti)héroe y la mirada privada sobre las historias coincidan con el aumento de lectoras femeninas de un género que siempre estuvo marcado por el adjetivo "masculino". Todo esto ha producido múltiples enriquecimientos del género, sobre todo en el plano formal y estilístico, tales como el hibridismo textual y la introducción de nuevas formas de narrar. Al mismo tiempo, tampoco podemos cerrar los ojos y no ver que en otras áreas periféricas, como Latinoamérica o el mundo árabe, incluso dentro de ese centro occidental, en las brechas e intercruces socioculturales que producen los fenómenos migratorios contemporáneos, se está dando una nueva literatura criminal. Reformuladora de las viejas estructuras, actúa como vehículo de denuncia y espacio visibilizador de la "marginalia", definida por Amir Valle como todo aquel espectro de sociedad invisible, la amplia masa de pobres y excluidos (96), desde Yasmina Khadra en Argelia-Francia a Rubem Fonseca en Brasil; Juan Hernández Luna en México; Daniel Chavarría y Leonardo Padura en Cuba; Raúl Argemí y Mempo Giardinelli en Argentina o Luis Sepúlveda y Roberto Bolaño en Chile, como tantos otros que están haciendo hoy un novedoso neopolicial ${ }^{1}$ en nuestro ámbito cultural. Noguerol, por su parte, subraya cómo el neopolicial latinoamericano se compone de "un corpus narrativo comprometido con la realidad que, desde los años setenta hasta nuestros días, ha reflejado las facetas más oscuras de la condición humana. Contrario al whodunit y adscrito al hard boiled, el neopolicial se carga de pesimismo para denunciar la corrupción omnipresente en unas sociedades en las que triunfa, definitivamente, el asesino" (párr. 54).

Respecto al estilo que caracterizaría a estos escritores, como explica García Talaván, "en lugar de acomodarse a la nueva estética [posmoderna] e interesarse por el éxito comercial de las publicaciones periódicas y por las vacuas manifestaciones pensadas para ser rápida y fácilmente consumibles, optan por las posiciones de la contracultura definitivamente politizada, corrosiva y rebelde" (73-4).

Desde la aparición de su novela Tres funerales para Eladio Monroy (2006), Alexis Ravelo (Las Palmas de Gran Canaria, 1971) se ha decantado decididamente por la narrativa adscrita a este género. La saga sobre el detective Eladio Monroy se completa

1 Según explica Amir Valle, este término fue acuñado por Paco Ignacio Taibo is para diferenciar el comportamiento de la novela negra en América Latina (96). 
con los títulos Solo los muertos (2008), Los tipos duros no leen poesía (2011) y Morir despacio (2012); novelas que encuentran en la ciudad de Las Palmas de Gran Canaria el espacio narrativo que le sirve para reflejar los procesos de la modernidad con todas sus contradicciones. En sus textos, Ravelo muestra interés por desarrollar una suerte de costumbrismo, algo que lo acerca a la narrativa de los escritores españoles del xix. Aunque su proyección en Latinoamérica no es aún muy amplia, su presencia comienza a hacerse notar: la editorial Revólver publicó recientemente en Argentina su novela La estrategia del pequinés, que había sido premiada en España ${ }^{2}$, y algunas de sus novelas se distribuyen en el continente.

De la producción de Alexis Ravelo, nos dedicaremos a dos textos en los que se aleja de las características formales de la serie de Eladio Monroy, para reflexionar sobre cuestiones como los espacios y la memoria, que forman parte de la La iniquidad: La noche de piedra (2007) y Los días de Mercurio (2010). Se trata de novelas que, a juicio de González Déniz, "nacen alrededor de atmósferas muy cerradas y que podríamos considerar muy cercanas al género negro" (párr. 3), o como las define Argemí, "que son muy negras pero de otra manera" (46), y en las que el mal se convierte, sin duda, en el tema principal y centro de reflexión, como ocurre, si bien ya de manera global, en la narrativa de Roberto Bolaño:

A veces puede aparecer como un tema secundario, como en Los detectives salvajes o, en otros casos, como el eje central sobre el que se articulan sus textos, como acontece en 2666, pero, sea como sea, la iniquidad tiene una poderosa presencia en la narrativa bolañiana. Bolaño aborda sus novelas, por lo general, desde las perspectivas de los investigadores o de los testigos que reconstruyen los asesinatos y no desde la mirada de los victimarios. De esta forma, deja en el misterio las razones que mueven al mal en su narrativa (Candia Cáceres 43).

\section{La noche de piedra (La iniquidad I)}

La noche de piedra, que inaugura la serie La Iniquidad de Alexis Ravelo, es una historia contemporánea: la de una matanza que altera la solo aparente tranquilidad del pueblo de San Expósito, pero que, como iremos viendo, va más allá del relato de ciertos violentos sucesos que sorprenden a esta comunidad, ya que su lectura nos empuja a mirar(nos). El texto se ubica en la más pura tradición del género negro clásico, por el estilo directo, sin florituras y con símiles y comparaciones que lo acercan a Chester Himes, o el efectivo manejo de la intriga y el suspense. Nos detendremos, sin

2 Entre otros reconocimientos, ha ganado el xxvir Premio Dashiel Hammett, de la Semana Negra de Gijón (2014); el Premio Novelpol 2014 a la mejor novela negra publicada en español en 2013 y el Premio Tormo Negro 2015, de las Casas Ahorcadas (Cuenca). Ravelo participó en el certamen Córdoba Negra 2014 y en 2016 será autor invitado a Buenos Aires Negra tras haber recibido el premio SN-BAN 2015 (Semana Negra-Buenos Aires Negra). 
embargo, en un aspecto muchas veces desatendido por la crítica literaria, pero que se nos impone como protagónico desde las primeras líneas, sobre todo porque estamos ante una novela coral. El hilo argumental, expuesto linealmente, es construido por el entrecruce de relaciones entre el cabo Casañas y su esposa Marta; la policía Estrella; Germán Bethancourt, el ejemplar hombre de negocios de la zona; la pareja de delincuentes formada por Julia y Nico; y Benito Marín, el tonto del pueblo, que, junto con un grupo de secundarios, va desfilando y conformando el paisanaje de San Expósito.

Este protagonista no es otro que el espacio, cuyo papel es resaltado desde las dos citas que funcionan como pórtico de la novela: una de Las ciudades invisibles de Italo Calvino y otra de El malestar en la cultura de Freud (con esa preposición locativa "en"); así, comenzamos la lectura con la idea de que habitar en sociedad es un infierno. También se impone la importancia del espacio cuando el horror de la tragedia es anunciado en las primeras líneas por un fenómeno físico-meteorológico: la tormenta que se avecina y se palpa en el aire, definida como una losa que caerá sobre el pueblo esa noche de piedra (tomado de un verso del Canto general de Neruda que es encontrado en el bolso de Julia, el cual ha subrayado), que da nombre a la obra.

Más allá del papel tradicional conferido por la teoría literaria al espacio, de otorgar verosimilitud a la ficción, el tratamiento que se hace de este elemento en La noche de piedra lo convierte en un verdadero paisaje humano y cultural. San Expósito es descrito con tanto detalle ${ }^{3}$, que podemos trazar un plano exacto de él. No son baladíes los nombres de los lugares como San Expósito o Roque del Malo. San Expósito, el nombre del pueblo, nos da la idea de un lugar sin ascendentes, huérfano de todo; como el infierno, es un mundo sin dios. El autor también propone un espacio literaturizado, habitado por el lector, cuando elige los topónimos, como la onettiana plazuela Juantacadáveres o la rulfiana calle Luvina. Al final, lo que se nos impone es el plano moral y no el geográfico: un espacio asfixiante, viciado, cargado, claustrofóbico, que no ofrece salidas... en definitiva, donde habita el mal, algo que se repite constantemente:

El coche patrulla se deslizó por la calle Principal de San Expósito, desierta bajo el infierno de agua y viento (Ravelo, La noche de piedra 34).

Salió del vehículo y entró en el cuartelillo diciéndose que el infierno no queda lejos; que, para ser exactos, el camino hacia el infierno pasa por San Expósito (163).

Entra en el coche y empieza a conducir hacia San Expósito. Piensa atravesar el pueblo como un rayo, bajo este sol del atardecer que pinta el cielo de anaranjados y rojos, color de muerte, color de infierno (261).

3 La mayoría de los nombres de las calles, plazas e instituciones ya habían sido utilizadas por el autor en el cuento “Antagonistas", que apareció en el volumen colectivo Ínsulas encantadas, editado por Anroart en 2005. 
San Expósito es claramente una región inventada, aunque podamos establecer semejanzas con las Islas Canarias y, en concreto, con la ciudad de Las Palmas de Gran Canaria, donde nació y vive el autor. De hecho, no es casualidad que el punto espacial más importante, por ser sede del conflicto y desenlace de la trama, se llame Roque del Malo, y que este término que señala un accidente geográfico sea considerado canarismo ${ }^{4}$. Esto nos permite hacer juegos entre la trama ficcional y acontecimientos de la realidad insular, como por ejemplo la especulación urbanística en connivencia con el poder político y el sector empresarial, y que representa la interesada amistad entre Germán y Onésimo, el alcalde. Así, este no lugar permite al autor la fabulación por no estar sujeto a un topos concreto, al tiempo que universaliza la historia y los personajes, a quienes podríamos encontrar en cualquier otro punto del planeta.

Tampoco puede obviarse que este pueblo está situado en una isla, con toda la carga que esta tiene en el imaginario simbólico-cultural de la tradición occidental. La isla es un micromundo, pequeño, cerrado, analizable, que refracta el macromundo; por eso se ha utilizado tanto como alegoría. De este modo, estos espacios privilegiados para el mito son tanto escenarios perfectos para la utopía, para un mundo ideal soñado y deseado, donde proyecta sus anhelos e ideales la sociedad, como para el infierno. En este caso, San Expósito se presenta como una distopía, que Galán Rodríguez define de la siguiente manera:

retóricamente, es el contrapunto de la errónea interpretación de "utopía" como 'lugar feliz' (>eu-topos); luego, "distopía" ha de entenderse como 'lugar de infelicidad'; en este sentido, las distopías conciernen a la estructura de una sociedad ficticia y no a su ubicación física, objetivo que sí es fundamental, por ejemplo, en las denominadas anti-utopías. En segundo lugar, y frente a otras denominaciones más interesadas en la dimensión política o en la sátira, el propósito es advertir didácticamente (de ahí su atractiva forma novelada) de un futuro apocalíptico que amenaza con anular al individuo, pero que puede ser corregido tanto en el espacio ficticio de la novela como en el presente real del autor (116).

Ya en otro aspecto, no hay que pasar por alto, aunque nos centremos en el espacio narrativo, el modo en que se relatan los hechos (presentados como reales, según las "Advertencias preliminares", pues supuestamente todos los datos han sido recogidos para su reconstrucción por el narrador -cuya identidad no se revelará-, gracias a la colaboración del sargento Vidal, de la Guardia Civil de la ciudad vecina de San Blas), a modo de polifonía discursiva. En la narración, en tercera persona, cada uno de los breves capítulos nos lleva de un personaje a otro, de un escenario a otro, saltando en ocasiones a la segunda persona, por medio de la cual el narrador parece dirigirse a los personajes. A través de una suerte de monólogo interior, escuchamos las verdaderas

4 Término no recogido por el DRAE. Según la Academia Canaria de la Lengua, en su primera acepción, es una elevación rocosa, muy escarpada; peñón. http://www.academiacanarialengua.org/palabra/roque/ 
voces y pensamientos de cada uno, todos complejamente trazados, ya que el autor opera la construcción de su psicología desde el interior mismo del lenguaje:

Fuiste guapa, Estrella. Lo fuiste. Pero pasó tu momento. Habrá quien te quiera, de hecho lo hay, pero no quien sienta pasión por ti. Para despertar pasiones hace falta algo que hace ya al menos diez inviernos que perdiste. Las estrías de tus muslos, el culo que se te empieza a caer... Sabes que quien te quiera, quien te quiere, lo hace por ternura, por apego, por otra cosa que no es eso que puede ofrecer cualquier jovencita o cualquier mujer de tu edad bien conservada. Ahora no eres más que una especie de marimacho. La vieja te ha pegado su olor a podrido (Ravelo, La noche de piedra 23-4).

Así, con esos saltos de personajes y de espacios narrativos, nos hallamos ante una geografía fragmentada: todos los personajes, desde sus espacios, conforman un coro de círculos concéntricos, ya que cada uno está interrelacionado con los otros, a los que toca e influye. Además, todos esos círculos giran, se mueven tocados por una misma sed: la del poder (aunque orientada en cada caso hacia diversos objetivos: dinero, libertad de vivir una pasión, escapar de San Expósito, escalar socialmente, poseer a los otros...), que tuerce poco a poco las primeras imágenes que nos formamos de esos personajes, sus apariencias rectas y moralmente aceptadas en sociedad, lo que se une al pulso del suspense y la sorpresa constante, como bien ha hecho notar Leandro Pinto:

[...] los pasos medidos y seguros de un Germán Bethencourt delicioso en su psicosis; las certezas de Sergio Casañas que se van tornando realidades (en cuanto al caso y, sobre todo, en cuanto a su relación marital), la oscura realidad de la cazadora cazada, de esa Julia de sentimientos volubles que se encuentra, de pronto, cautiva de su supuesta víctima, y, sobre todo, del desarrollo y crecimiento de la relación lésbica que, aunque vista como inmoral por la cerrada mentalidad de los puebluchos en los que se ambienta la narración, acaba siendo la sustancia sentimental más pura de toda la novela (hasta que detona, claro) (párr. 3).

En esta novela no hay héroes ni mensaje moral: hasta el tonto Benito Marín participa y se mancha las manos, a su medida, en la tragedia. Si bien el personaje de Germán parece el más poderoso, todos quieren sacar provecho del arreglo (título de la tercera parte) que cada uno se ha formado en su cabeza. Todos caen; todo, simplemente, se desmorona, lo que es un ataque al sistema que los envuelve, pero también -y sobre todo- al lector, a ese "nosotros mismos" que conformamos-hacemos-somos ese sistema. En este sentido, podríamos señalar -como hace Nichols para Mempo Giardinelli- que Ravelo crea un espacio narrativo en el que nos "invita a explorar, cuestionar y cruzar una serie de fronteras: tales como las fronteras entre la ficción y la realidad, la ética y la estética" (Nichols, "Siguiendo las pistas" 495).

Por último, no podemos dejar de tratar un interesantísimo rincón donde se desarrolla buena parte de la trama: la siniestra casa de Germán, instalada sobre el Roque, 
con poderosos ecos del psicoanálisis: el sótano, la zona más profunda, lugar del Ello, almacén de las pulsiones ilícitas, donde este personaje quiere someter a sus víctimas, frente a la primera planta, donde se relaciona el señor Bethancour racionalmente con la sociedad. Esta división también se observa en cierta cinematografía: El sirviente (Joseph Losey, 1963), La huella (Joseph Mankiewicz, 1972) y El coleccionista (William Wyler, 1965). Este espacio, pues, podría ser analizado desde la perspectiva de Jung, quien había concebido la casa como instrumento de análisis para el alma (Cassigoli 27).

En resumen, con la construcción del paisaje de esta novela - una auténtica cacotopía-, Ravelo reafirma la intuición de Binswanger, para quien "la situación espiritual de la existencia humana sólo puede ser comprendida a partir de un esquema espacial" (Llarena González 27). La novela se convierte en sí misma en espacio para la ética o, mejor, para la antiética, un no-lugar privilegiado para el estudio de las almas, del mal y de la muerte sin esperanza, sin horizonte posible de resurrección.

\section{Los días de Mercurio (La iniquidad ॥)}

Los días de Mercurio es un relato en primera persona que podría vincularse, a la distancia, con la escritura de Manchette en Fatal (1987), aunque fundamentalmente con Camus, como apunta Doreste ${ }^{5}$. Ravelo, que define el estilo de Manchette como "rápido, eficiente, casi forense", señala:

Esta parquedad de estilo, que algunos relacionarán con su cercanía al cine y al cómic, podría tener que ver con la rabia. Una rabia que surge en contra del sistema, una rabia muy marcada en todas sus novelas, que están escritas con las tripas por alguien que sabe perfectamente a qué lector se dirige y que es muy consciente de las ideas y sentimientos que desea despertar en él. Alguien que intuye que la literatura es una bomba de relojería a punto de estallar, haciendo saltar los trípodes del camelo del sistema, como suele ocurrir en los tercios finales de sus obras, cuyas páginas son recorridas por desbordados ríos de sangre ("Libros de saldo" párr. 7).

Podríamos afirmar que Los días de Mercurio se inscribe dentro de las escrituras de la memoria histórica que se han venido produciendo en estas últimas décadas. Pedro, su protagonista, no deja de ser un huido en el contexto de la posguerra española, época que viene a ejemplificar los síntomas de una sociedad problemática, destinada a repetir constantemente los enfrentamientos entre liberales y conservadores, como ya advirtiera

5 "Acabada la última frase, cerrado el libro con el regusto de haber leído otra vez, de otra manera, de forma diferente, la vida de Meursault, volvemos a leer, esta vez más despacio, intentando que el galope del estilo no nos arrastre y nos impida encontrar el auténtico sentido a la obra" (párr. 2). 
en su momento Mesonero Romanos ${ }^{6}$. La narración es heredera de la "mirada evaluadora y, hasta cierto punto, frustrada hacia la realidad política española" (Song 459-60) de Vázquez Montalbán, lo mismo que podríamos afirmar de La última tumba (2013).

La novela, situada en un lugar impreciso del Pirineo aragonés, aborda también dentro del contexto histórico (los años cincuenta) el tema de los maquis ${ }^{7}$. Su protagonista, que se hace llamar Pedro, es un maquis que ha perdido cualquier esperanza y trabaja de camarero en el bar de un pueblo:

Me bajé del monte porque me había cansado de andar de acá para allá. Demasiados años masticando el miedo. Demasiada esperanza tirada por los caminos, en el fondo de los barrancos, en lo profundo de los bosques, en la aspereza de las laderas. Al menos al principio. Y, después, una vez disuelto el grupo, muchas identidades y lugares y oficios distintos, hasta convertirme en el fantasma de mí mismo (Ravelo, Los días de Mercurio 55).

Los días de Mercurio, así, se ubica en una corriente no muy explorada por los novelistas, pero que cuenta con significativos cultores, como señalaba Izquierdo en 2002:

En tiempos de la democracia se han escrito, teniendo al maquis como protagonista, unas cuatro novelas, tomando a la trilogía, El color del crepúsculo (1995), Maquis (1997) y La noche inmóvil (1999), de Alfons Cervera (Gestalgar, Valencia, 1947) como una unidad, siendo las otras obras Luna de lobos (1985) de Julio Llamazares (Vegamián, León, 1955), El puente de hierro (1998) de César Gavela (Ponferrada, León, 1953) y La noche de los cuatro caminos (2001) de Andrés Trapiello (Manzaneda de Torío, León, 1953) (106).

Por su proximidad temática con la novela de Ravelo, dentro de este conjunto destacamos Luna de lobos, ambientada en las montañas de León, que conoció una adaptación cinematográfica homónima dirigida por Sánchez Valdés (1987). En ella, un grupo de soldados republicanos secuestra al dueño de una mina y exige dinero a cambio de su vida; con este, podrán huir a Francia. Las novelas de Cervera, por su parte, han sido también objeto de adaptación cinematográfica, como en Silencio roto, de Montxo Armendárix en 2001 (Izquierdo).

En el caso de Los días de Mercurio, Pedro recurrirá a la extorsión del empresario y jefe local de la Falange, Uribe, para obtener el dinero que le ayude a huir también de España, pero ello será resultado de un cúmulo de circunstancias que lo dirigirán a

6 "Concluía la guerra extranjera pero surgía al mismo tiempo la más intestina y porfiada de los españoles entre sí, lucha fatal entre lo pasado y el porvenir, que dura todavía; que nosotros heredamos de nuestros padres y transmitimos a nuestros hijos y nietos, y que, Dios mediante, transmitirán estos últimos a los suyos en toda su integridad. Pero entonces lo pasado seremos nosotros, y el porvenir... ¡a saber quién será!” (Mesonero Romanos 155).

7 "Durante la guerra y posguerra españolas, en el periodo de 1936 a 1952, se dio el fenómeno de la lucha guerrillera antifranquista en las zonas rurales, perviviendo hasta 1963 en las ciudades. Será lo que la propaganda del régimen denomonó como maquis, bandas de bandidos o terroristas " (Izquierdo 105). 
esa situación a través de una serie de crímenes de los que es voluntario o involuntario autor. El planteamiento de la novela de Ravelo es muy sencillo: en un mundo donde la traición es el motor en las relaciones interpersonales, lo único que no puede ser traicionado es la memoria.

Pero antes de continuar con el análisis de la novela como reflejo de un contexto histórico marcado por la memoria histórica, es preciso realizar algunas reflexiones al hilo de la literaturización de la historia.

Nichols señala que los escritores latinoamericanos del siglo xx "mezclan ficción e historia para examinar las compenetraciones mutuas de sus discursos respectivos en la formación de la identidad moderna de Latinoamérica" ("A los márgenes" 300); ello ha de entenderse, de acuerdo con Fajardo, como una "reescritura ficcionalizada del discurso histórico (ya de hecho ficcionalizada)" (26). Literatura e historia, señala Franken, quien sigue a Balderston, son "artes del desciframiento de una verdad secreta que puede ser conocida solamente en forma incompleta dado que el acceso a la verdad es siempre parcial y frustrante" (101). En esa línea se mueve la narración de Ravelo, quien está ficcionalizando un discurso, el de la posguerra española, que se ha mantenido y se mantiene ficcionalizado hasta nuestros días.

No hay que olvidar que el debate en torno a la memoria histórica en España es una cuestión candente, como señalan Aróstegui, Marco y Gómez, para quienes el proceso de revisión del pasado que se ha venido produciendo desde fines del siglo xx revela la falta de consenso social, pero fundamentalmente político, en torno a la guerra civil y al franquismo. La reparación moral de los represaliados del franquismo, que es lo que persiguen las asociaciones por la recuperación de la memoria histórica, ha llevado y lleva a determinados sectores de la sociedad española a promover

un revisionismo que defiende la dictadura, juzgando, acusando y culpando a todos los que arrojan luz en otra dirección. Los excesos represivos del franquismo quedan así justificados por los cometidos durante la República. Los "crímenes rojos" son reutilizados con la fuerza mediática de estos sectores que se oponen precisamente a que el debate público sobre la memoria tenga normalidad y continuidad. Por estas y otras muchas razones, la memoria histórica en España ha seguido un proceso de difícil articulación (79).

El procesamiento de la historia que realiza Ravelo en la novela, y que lo emparenta, como señalamos, con Vázquez Montalván, pero también con Goytisolo en sus memorias En los reinos de Taifa (1986), refleja los problemas de la sociedad española, tanto en el país como fuera de él, durante el largo periodo del franquismo por las profundas contradicciones y sinsentidos de la resistencia ideológica y el acomodamiento de sus dirigentes: "Los mismos que en el 48 nos abandonaron a nuestra suerte porque la federación, porque el partido, porque José Stalin y su puta madre habían decidido que había que optar por un cambio de estrategia. // ¿Los jodidos? Los de siempre” (Ravelo, Los días de Mercurio 57). 
La figura del maquis, como en el siglo xix la del bandolero, despierta indudablemente simpatía, puesto que es la representación de la resistencia antifranquista al orden establecido, y revive el idealismo romántico. Pero el maquis no deja de ser un derrotado que ha sido incapaz de asimilar un proceso irreversible y que se verá obligado a sobrevivir. Ravelo no proyecta una imagen victoriosa de su héroe, porque aquel dejó de serlo desde el momento en que tomó conciencia de su situación y de su derrota. En este sentido, solo le queda aferrarse a su memoria, a la que da carta de naturaleza como documento veraz cuando adquiere carácter escrito: "El cuaderno es mío y pienso escribir en él lo que se me dé la gana” (Los días de Mercurio 10). La escritura, en este sentido, está planteada como un ejercicio de reflexión histórica, testimonio del fracaso del ser humano: "Es necesario reflexionar sobre todo esto, para que el asunto se entienda como es debido. Para, al menos, poder entenderlo yo. Quiero decir: yo hice lo que hice y se supone que soy lo que soy, pero yo, en realidad, no soy el que hizo aquello, ni el que es eso que dicen que soy" (10).

Pedro no deja de ser testigo de la sociedad de posguerra de provincias desde su posición de camarero de un bar; ello permite al lector contemplar la verdad de una sociedad que tiene sentido en la ocultación de identidades no solo políticas, sino también sexuales. Uribe, que mantiene relaciones con un antiguo compañero de colegio de Pedro (un puto), afirma: "aquí no hay maricones. No hay maricones, ni comunistas ni anarquistas ni masones. Acabamos con todos en el 36. Y con los que no pudimos acabar, hicimos un paquete y les dimos una patada en el culo y los mandamos fuera, para que no volvieran más" (68). Los personajes de Ravelo luchan contra su pasado, que los acusa y los ha condenado, y contra su situación en el presente, de la que no se pueden sustraer.

Los días de Mercurio viene precedida de tres citas: la primera, de Jaime Gil de Biedma; la segunda, de Luis Cernuda, y la tercera, de Herman Melville. Los textos de Biedma y Cernuda apuntan hacia los problemas de la existencia y de la memoria; la frase de Melville ("I know where I am"), tomada de Bartleby, the scrivener, refleja el problema de la identidad en conflicto con la sociedad.

La novela negra no deja de ser una evolución de la novela decimonónica, definida por los conflictos de los personajes con la sociedad en que han de vivir. Este planteamiento, que ya encontramos en El Quijote mediante la tensión entre el querer ser y el deber ser, alcanza su máxima expresión en la novela negra. Los personajes de las novelas naturalistas-realistas, por ejemplo, en el caso de las novelas de Pérez Galdós, "tienen que doblegarse a las leyes sociales. Fuera de la sociedad sólo existe el abismo, la locura, la anarquía” (Oleza 103). Ante la imposibilidad de querer ser en una sociedad que impone sus condiciones, la única salida que les queda es el suicidio o la marginación. Oleza apunta, en este sentido, que "la tragedia de Isidora, con su desenlace en la prostitución y en la cárcel (donde todavía grita "Soy noble, soy noble. No me quitaréis mi nobleza, porque es mi esencia, y yo no puedo ser sin ella"), no es un caso anormal, una excepción" (104), producto de una enfermedad hereditaria, la 
locura. En el caso de la novela de Ravelo, la tragedia de los personajes es producto de otra enfermedad, consecuencia de la guerra, cuyas secuelas permanecen y definen las relaciones de los personajes con el medio.

Pedro, el personaje de Los días..., acabará actuando de una manera similar a Isidora Rufete, pero con una diferencia fundamental. Isidora lucha porque se reconozca su nobleza y cree saber quién es; Pedro parte de un problema de identidad -"Lo difícil, lo casi imposible, es saber quién se es; mirar una foto, enfrentarse a un espejo, leer unas iniciales escritas tras un nombre de pila en una página de sucesos y decir: ese soy yo" (10)- y llega a comprender -y en el proceso también el lector llega a la comprensión- que sabe dónde está. Ello lo emparenta con Bartleby, otra figura problemática de la literatura, como Isidora. Ravelo señala, a propósito del personaje de Melville:

si el hombre está dominado por su conciencia y experiencia de la muerte; y si la sociedad no es más que una estructura que nos garantiza una supervivencia virtual, $[\ldots]$ entonces Bartleby puede ser visto como un individuo que acepta la inutilidad de ese recurso y se niega a luchar contra lo ineluctable, "desenchufándose" de esa máquina. En este orden de cosas, su "mecanismo de desconexión" sería su negativa a continuar con lo establecido. [...] Por eso ha preferido no continuar luchando. Por eso se niega a perpetuar su permanencia en ese conjunto informe que lucha contra lo inevitable. Bartleby, pues, sería un individuo a quien su lucidez sume en la des-esperanza: un hombre que ha descubierto la más terrible de las verdades y que hace un ejercicio de honestidad intelectual, rehúsa mentir y espera, paciente, ahora sí, estoicamente, porque, al contrario que los demás, él sí sabe dónde está (Ravelo, "Bartleby" párr. 1).

Lo inevitable es también la locura de Isidora y la condena de Pedro, porque, en el fondo, la novela ha de desembocar en un orden que se impone inexorablemente. Sin embargo, en el caso de La desheredada, Isidora acaba perdiendo su nombre: "Así es el mundo: unos se quedan y otros se van. Yo me fui, ¿te enteras? Yo me he muerto. Aquella Isidora ya no existe más que en tu imaginación. Esta que ves, ya no conserva de aquella ni siquiera el nombre" (Pérez Galdós 266).

En Los días... los nombres son clave: se asocian a la identidad, sin lugar a dudas, pero también a un orden social que algunos personajes se niegan a asumir. Ravelo presenta ese conflicto que surge entre las dos Españas y entre dos maneras de percibir el mundo:

- Aquí somos gente de orden. Por eso todos tenemos nombre, como está mandado. ¿Cuál es el suyo?

Noté cómo las carnes del mentón del gordo temblaban ligeramente. Debía de estar ocurriendo algo similar con sus rodillas.

- Miguel Hernández Altolaguirre -acabó por decir, tendiendo nuevamente la mano hacia Uribe, quien la estrechó con fuerza (40). 
Pedro viene a proclamar, al final de la novela, la libertad de morir siendo otro, aferrado a la posibilidad de mantener fuera de la memoria de los otros la suya propia. En este sentido, proclama su particular "I know where I am" y la actitud del personaje se aproxima a Bartleby: "Me lo arrebatasteis todo: la ilusión, la juventud, la confianza, las ganas de vivir, la capacidad de amar. Me lo quitasteis todo, salvo este último placer, esta definitiva e íntima venganza: la de mantener mi verdadero nombre en secreto, la de que mi verdadero nombre continúe siendo, para siempre, mío” (184).

\section{A modo de conclusión}

Indiscutiblemente, dentro del género negro, con estas novelas Ravelo se aparta de las corrientes de la nueva novela negra actual tan de moda hoy en día, y entronca con la mejor tradición de la novela negra española de los años setenta y ochenta. Ravelo recupera el carácter social y la dimensión filosófica de este tipo de textos a través de un interesantísimo tratamiento del espacio y de la reconstrucción de la memoria histórica. Como hemos visto, al mismo tiempo, se alinea con lo más puro del noir, que, según Nichols, "representa la reacción a una crisis cultural y ofrece una representación de psiques fragmentadas, individuos alienados, y una frustración general con las promesas fracasadas del 'sueño americano"' (“A los márgenes" 299).

Ello no significa que sus recursos formales y referencias culturales se hayan anquilosado; al contrario, nuestro autor es capaz de acoger técnicas e hipertextualidades de las nuevas corrientes narrativas abiertas por la posmodernidad (cabe destacar la introducción de la música o la polifonía narrativa antes mencionada), de manera parecida a las aportaciones que desde Latinoamérica vienen haciendo los escritores que cultivan el género. Desde su tiempo, responde a las interrogantes que la sociedad actual plantea, como apuntaba Vázquez Montalván, para quien la labor del escritor del género, más allá del escepticismo propio de la posmodernidad, es la de efrentarse a la realidad para darse "cuenta [de] que está deshistorificada y que ha de devolverle un discurso histórico" (96). Eso es precisamente, lo que se propone Ravelo, tal como le confiesa a Raúl Argemí: "[...] aunque solo me dedique a escribir ficciones (o incluso ensayo), sí que tengo ciertas preocupaciones sociopolíticas, éticas o, incluso, ontológicas que no puedo evitar que se cuelen en mis textos. Más que una obligación autoimpuesta, es una circunstancia, algo inevitable que, ya que no puedo soslayar, prefiero asumir" (párr. 47).

En su propuesta, Ravelo se acerca a la novela neopolicial latinoamericana (y a la criminal del tercer mundo de nuestros días), alternativa a la novela negra comercial que, a decir de Diego Trelles Paz, "incorpora y reformula algunas estructuras y convenciones del policial duro norteamericano, compartiendo algunos rasgos formales con la ficción hispanoamericana contemporánea" (79). Se mueve, pues, entre lo propio y lo ajeno para dar cuenta de un otro tipo de sociedades atravesadas por la violencia. 
Pero esta alineación solo se consigue desde una vocación universalista, que no quiere quedarse enmarcada en España o en Canarias, lo que consigue con la creación de regiones ficticias y la imposición de la anonimia para esos espacios de iniquidad que multiplican, además, el efecto de la sugerencia.

No podemos dejar de caer en la tentación de usar la cita de Stalin que introduce Mo Yan al inicio de Las baladas del ajo: "Los novelistas siempre tratan de alejarse de la política, pero la novela en sí gira en torno a la política. A los novelistas les preocupa tanto el 'destino del hombre' que suelen perder de vista su propio destino. Y ahí radica su tragedia" (9). Algunos, por la gracia de dios -o del demonio-, se empeñan aún en ser infames.

\section{Referencias}

Agencia EFE. "El escritor griego Petros Márkaris dice que la novela negra 'es la más religiosa del mundo"'. La voz libre. 16 Jul. 2011. Web. 21 Dic. 2012.

Argemí, Raúl. "Lejos de los centros editoriales parecemos escritores invisibles". Miradas al sur. 23 Ago. 2014. Web. 19 Ago. 2015.

Aróstegui, Julio, Marco, Jorge y Gómez, Gutmaro. "Visiones, enfoques y evidencias: la Cátedra Memoria Histórica del siglo xx”. Historiografías 3 (2012): 77-88. Impreso.

Balibrea, Mari Paz. "La novela negra en la transición española como fenómeno cultural: una interpretación”. Iberoamericana 2.7 (2002): 111-118. Impreso.

Bourdieu, Pierre. Las reglas del arte. Barcelona: Anagrama, 2001. Impreso.

Candia Cáceres, Alexis. “Todos los males el mal. La 'estética de la aniquilación’ en la narrativa de Roberto Bolaño”. Revista Chilena de Literatura 76 (2010): 43-70. Impreso.

Cassigoli, Rossana. "Poética, morada y exilio: en torno a Gaston Bachelard". Gaston Bachelard y la vida de las imágenes. Ed. Blanca Solares. México: unam, 2009. 59-89. Impreso.

Cervera, Alfons. “¿Por qué dejé de leer novela negra?”. Universitat de Valencia. 2010. Web. 22 Dic. 2014.

Cordón-García, José-Antonio. “La paradoja de los géneros. La novela negra en el ámbito editorial”. Geografías en negro. Escenarios del género criminal. Ed. Àlex Martín Escribà y Javier Sánchez Zapatero. Barcelona: Montesinos, 2009. 79-96. Impreso.

Doreste Zamora, Javier. “Alexis Ravelo escribe novelas de amor”. Canarias social. 2011. $<$ http://www.canariassocial.com.mialias.net/opinion/item/9343-alexis-raveloescribe-novelas-de-amor>. Web. 28 Ene. 2015.

Fajardo Valenzuela, Diógenes. "Anotaciones sobre literatura colonial y su historia”. Leer la historia: Caminos a la historia de la literatura colombiana. Bogotá: Universidad Nacional de Colombia, 2007. 23-59. Impreso. 
Franken, Clemens A. "La novela negra argentina y chilena de (pos-) dictadura". Taller de Letras 49 (2011): 97-107. Impreso.

Galán Herrera, Juan José. “El canon de la novela negra y policíaca”. Tejuelo 1 (2008): 58-74. Impreso.

Galán Rodríguez, Carmen. "Logomaquias y logofilias: distopías lingüísticas en la ficción literaria”. Anuario de estudios filológicos 30 (2007): 115-129. Impreso.

García Talaván, Paula. "La novela neopolicial latinoamericana: una revuelta éticoestética del género". Cuadernos Americanos 148 (2014): 63-85. Impreso.

Golubov, Nattie. "La masculinidad, la feminidad y la novela negra". Anuario de Letras modernas 5 (1991-1992): 99-121. Impreso.

Gómez O., Cristián. "Reseña del Libro Rascacielos”. Cyber Humanitatis 52 (2010): s.p. Web. 23 Ene. 2015.

González Déniz, Emilio. "Escritores sin escritorio pero con obra”. Canarias7. 5 Jul. 2010: s.p. Web. 10 Dic. 2014.

Izquierdo, José María. "Maquis: Guerrilla antifranquista. Un tema en la literatura de la memoria española”. Romansk Forum 16 (2002): 105-116. Web. 15 Dic. 2014.

Llarena González, Alicia. Espacio, identidad y literatura en Hispanoamérica. Culiacán Rosales, Sinaloa: Universidad Autónoma de Sinaloa, 2007. Impreso.

López Martínez, Marina. "La literatura de lo irreparable y su ideología”. Cédille. Revista de estudios franceses 7 (2001). 174-189. Impreso.

Mesonero Romanos, Ramón de. Memorias de un setentón. Barcelona: Crítica, 2008. Impreso.

Nichols, William J. “A los márgenes: hacia una definición de 'negra”. Revista Iberoamericana 76.231 (2010): 295-303. Impreso.

---. "Siguiendo las pistas de la novela negra con Mempo Giardinelli". Revista Iberoamericana 76.231 (2010): 495-503. Impreso.

Noguerol Jiménez, Francisca. "Neopolicial latinoamericano: el triunfo del asesino". Ciberletras: Revista de crítica literaria y de cultura 15 (2006). Web. 20 Jul. 2014.

Oleza, Joan. La novela del XIx: del parto a la crisis de una ideología. Valencia: Bello, 1976. Impreso.

Pérez Galdós, Benito. La desheredada. Alicante: Biblioteca Virtual Miguel de Cervantes, 2001. Web. 2 Feb. 2015.

Pinto, Leandro. "La quermés de la iniquidad". Blog El Disparaletras. 24 Ene. 2012: s.p. <http://leandropinto.jimdo.com/2012/01/24/la-querm\%C3\%A9s-de-lainiquidad >. Web. 10 Ene. 2015.

Ravelo, Alexis. "Bartleby, el escribiente (y 3)". Ceremonias. 21 Nov. 2006: s.p. Web. 15 Ene. 2013.

---. La noche de piedra (La iniquidad I). Las Palmas de Gran Canaria: Anroart Ediciones, 2007. Impreso.

---. Los días de Mercurio (La iniquidad II). Las Palmas de Gran Canaria: Anroart Ediciones, 2010. Impreso. 
---. "Libros de saldo, 2. 'Fatal', de Jean-Patrick Manchette". Revista Calibre 38. 14 Mar. 2012: s.p. Web. 10 Ene. 2013.

---. La última tumba. Madrid: Edaf, 2013. Impreso.

Salgado, Ángeles. "Reflexiones sobre el boom de la novela negra sueca (o por qué no acabaré de leer la trilogía Millennium de Stieg Larsson)”. Synthesis 54 (2010): 1-3. Impreso.

Sánchez Zapatero, Javier y Ángel Martín Escribá. “Teoría e historia de las sagas policiales en la literatura española contemporánea (1972-2007)”. Dicenda. Cuadernos de Filología Hispánica 28 (2010): 289-305. Impreso.

Song, Rosi H. "En torno al género negro: ¿la disolución de una conciencia ética o la recuperación de un nuevo compromiso político?”. Revista Iberoamericana 76.231 (2010): 459-475. Impreso.

Trelles Paz, Diego. "Novela policial alternativa hispanoamericana (1971-2005)”. Aisthesis 40 (2006): 79-91. Impreso.

Valle, Amir. "Marginalidad y ética de la marginalidad en la nueva ciudad narrada por la novela negra latinoamericana". Anales de Literatura Hispanoamericana 36 (2007): 95-101. Impreso.

Vázquez Montalbán, Manuel. La literatura en la construcción de la ciudad democrática. Barcelona: Crítica, 1998. Impreso.

Yan, Mo. Las baladas del ajo. Madrid: Kailas Editorial, 2008. Impreso.

Recibido: 13 noviembre 2014

Aceptado: 10 agosto 2015 